\title{
Learning objects: Mediating the Construction of Pedagogical Knowledge in the Educational Process of Agricultural Science Undergraduate
}

\author{
http://dx.doi.org/10.3991/ijes.v2i1.3670
}

Gislene M.C. Raymundo, Instituto Federal Catarinense - Câmpus Araquari, Araquari/SC, Brazil

Sandra M. Cunhasque, Instituto Federal Catarinense - Câmpus Araquari, Araquari/SC, Brazil

André L.F. Souza, Instituto Federal Catarinense - Câmpus Araquari, Araquari/SC, Brazil

Abstract - In a rapidly changing world, new technologies have been developed in order to improve the learning process. The spread of information and communication provide a way to develop new learning resources. Therefore, this work describes an experience with some undergraduate students in the production of videos as learning objects. The students were organized in small groups and developed different topics related to lesson planning. Findings show that all students reached the goals of the activity, making connections between the worked topics and the teaching practice. In addition, according to the students the activity enabled them to use the learning objects in the organization of their pedagogic work.

\section{Objetos de aprendizagem: mediando a construção de conhecimentos docentes no processo formati- vo do licenciado em Ciências Agrícolas}

\author{
Gislene M.C. Raymundo, Sandra M. Cunhasque e André L.F. Souza \\ Instituto Federal Catarinense - Câmpus Araquari, Araquari/SC, Brasil
}

\begin{abstract}
Resumo-Em um mundo de rápidas mudanças, novas tecnologias têm sido desenvolvidas para melhorar o processo de aprendizagem. A difusão da informação e da comunicação fornece um grande potencial para o desenvolvimento de recursos de aprendizagem. Desta forma, este trabalho descreve uma experiência com alguns alunos de graduação no desenvolvimento de vídeos na forma de objetos de aprendizagem. Estes estudantes foram organizados em pequenos grupos e desenvolveram diferentes tópicos relacionados ao planejamento escolar. Foi observado que todos os grupos alcançaram o objetivo da atividade proposta, fazendo conexões entre a temática trabalhada e a prática pedagógica. De acordo com os estudantes, a atividade contribuiu para capacitá-los para o uso de objetos de aprendizagem na organização de sua futura ação docente.
\end{abstract}

Palavras-chave-objetos de aprendizagem, planejamento escolar, vídeos

\section{INTRODUÇÃO}

Este trabalho tem como objetivo relatar uma experiência de ensino com os alunos do quinto semestre do curso de Licenciatura em Ciências Agrícolas, no Instituto Federal Catarinense - Câmpus Araquari, na disciplina de Práticas Pedagógicas e sua Organização. Com o intuito de desenvolver as habilidades e conhecimentos referentes à docência por meio do uso das novas tecnologias, propôsse aos acadêmicos a produção de materiais educacionais digitais na forma de objetos de aprendizagem (OA), espe- cificamente a produção de vídeos educacionais referentes ao planejamento escolar.

Desta forma, a proposta deste trabalho foi contribuir com a percepção de futuros professores para a importância da inserção de recursos e procedimentos didáticos no planejamento de sua prática pedagógica, mediados pelas novas tecnologias, como forma de promoção de aprendizagem mais interativa com vistas à construção do conhecimento e saberes docentes.

\section{DESENVOLVIMENTO}

O uso das tecnologias da informação e comunicação permite aos docentes vivenciarem diferentes maneiras de mediar as situações de ensino e aprendizagem, além de possibilitar a criação de novos e diversificados procedimentos didáticos. Na era da informação, comportamentos, práticas e saberes se alteram com extrema velocidade, refletindo em modificações significativas sobre as tradicionais formas de pensar e fazer educação [1].

Nesse sentido, é necessário (re)significar as situações didáticas, adequando-as às novas demandas sociais, políticas e tecnológicas da era da informação, buscando novas alternativas para as velhas questões da aprendizagem e, assim, contribuir para a formação do indivíduo para ser sujeito ator de sua prática social e profissional.

Analisando essa temática, Kenski (2006, p. 27) [1] ressalta que é necessário "abrir-se para novas educações resultantes de mudanças estruturais nas formas de ensinar e aprender possibilitadas pela atualidade tecnológica - é o desafio a ser assumido" por todos aqueles que estão inse- 
ridos na sociedade contemporânea, de forma especial pelos profissionais da educação.

Segundo Lampert (2009) [2], o uso da internet, especificamente do computador, configura-se como um poderoso veículo de comunicação e instrumento pedagógico do qual o professor de qualquer nível de ensino poderá lançar mão para incentivar os alunos e ressignificar o processo de ensino e aprendizagem. Veríssimo (2009) [3], também destaca que o uso das novas tecnologias no processo educacional torna-o mais dinâmico, atrativo e fascinante, sendo possível dividir a vida em antes e depois dele.

Nessa perspectiva, o uso adequado dessa ferramenta tecnológica constitui condição para melhorar a qualidade do ensino e adequá-lo à realidade. No entanto, o grande desafio colocado aos educadores, atualmente, é dominar as tecnologias da comunicação e informação e ter conhecimento do que cada uma tem a oferecer para viabilizar o processo de ensinar e de aprender.

Moran (2003, p. 45) [4], ao analisar essa situação afirma que:

Precisamos reinventar a forma de ensinar e aprender, presencial e virtualmente, diante de tantas mudanças na sociedade e no mundo do trabalho. Os modelos tradicionais são cada vez mais inadequados. Educar com novas tecnologias é um desafio que até agora não foi enfrentado com profundidade. Temos feito apenas adaptações, pequenas mudanças. Agora, na escola e no trabalho, podemos aprender continuamente, de forma flexivel, reunidos numa sala ou distantes geograficamente, mas conectados através de redes.

O uso das novas tecnologias da informação e comunicação aponta aos docentes que há outras maneiras de ter acesso a situações de aprendizagem e procedimentos de ensino e que por mais que tenhamos a nostalgia de outros instrumentos e procedimentos de ensino podemos afirmar que, neste contexto, os diversos tipos de mídias caracterizam-se como cúmplices imprescindíveis que possibilitam a criação de novos recursos didáticos e viabilizam a interatividade na construção do conhecimento.

No intuito de compartilhar saberes e reflexões sobre a prática pedagógica docente e ampliar as possibilidades de intervenções significativas no processo ensinoaprendizagem-conhecimento, discutiremos neste estudo o uso e a produção colaborativa dos objetos de aprendizagem no processo formativo de acadêmicos de Licenciatura em Ciências Agrícolas.

Trata-se de um projeto desenvolvido com os alunos que cursam o quinto semestre do curso de Licenciatura em Ciências Agrícolas do Instituto Federal CatarinenseCâmpus Araquari, na disciplina de Práticas Pedagógicas e sua Organização. Durante o projeto propôs-se aos acadêmicos a produção de materiais educacionais digitais na forma de objetos de aprendizagem (OA).

De acordo com o grupo Learning Objects Metadata Workgroup do Institute of Electrical and Electonics Engineers (IEEE) [5], objetos de aprendizagem (Learning Objects) são definidos como uma entidade, digital ou não digital, que pode ser usada e reutilizada ou referenciada durante um processo de suporte tecnológico ao ensino e aprendizagem.

Diante dos desafios existentes no contexto escolar, a produção de materiais educacionais digitais na forma de objetos de aprendizagem, constitui uma possibilidade de o professor trabalhar conceitos e conteúdos de forma colaborativa e interativa.
Segundo Behar (2009) [6] a utilização de objetos de aprendizagem possibilita uma nova concepção de aprendizagem apoiada pela tecnologia, na qual o professor abandona o papel de transmissor de informação para desempenhar um papel de mediador na construção do conhecimento.

Entre as diversas possibilidades de objetos de aprendizagem trabalhou-se com a produção e utilização de vídeos educacionais envolvendo a compreensão teórico-prática de conteúdos referentes ao planejamento escolar, possibilitando a reflexão sobre as seguintes temáticas: tipos de objetivos, conceito de conteúdos escolares, concepção de currículo e instrumentos avaliativos.

Dessa forma na construção desse objeto de aprendizagem os acadêmicos foram desafiados a relacionar o conteúdo trabalhado no curso de formação docente, especialmente na disciplina de Práticas Pedagógicas e sua Organização com a prática de planejar a ação docente. Também tiveram a oportunidade de sistematizar conhecimentos, retomar a compreensão de conceitos e metodologias que envolvem a organização da prática pedagógica.

Existem muitos objetos de aprendizagem que podem ser utilizados na prática pedagógica, compreendendo textos completos, histórias, imagens em movimento, som, softwares educacionais, hipertexto, experimentos práticos, mapas, gráficos, atividades interativas, simulações e clipes de áudio e vídeo que podem ser utilizados por professores e alunos em diferentes momentos do processo formativo. No entanto, optou-se por trabalhar com os vídeos devido à possibilidade de desenvolver uma leitura reflexiva desses meios, extrapolando o papel passivo da recepção da imagem e do som.

Nesse sentido buscou-se por meio desse projeto proporcionar aos futuros docentes a compreensão do uso pedagógico da web como um novo espaço educativo, permitindo ampliar as reflexões sobre o papel das tecnologias da informação e comunicação na educação e a possibilidade de colocar em prática novas situações didáticas que se caracterizam essencialmente pela interatividade entre os sujeitos envolvidos no processo de ensinar e de aprender.

Essa experiência permitiu que os acadêmicos percebessem que os objetos de aprendizagem são elementos de uma nova metodologia de ensino e aprendizagem baseada no uso do computador e da internet. É uma tecnologia recente que abre caminhos na educação a distância, e como material de ensino para a aula presencial, trazendo inovações e soluções que podem beneficiar a todos os envolvidos no processo de ensino e aprendizagem.

Os acadêmicos sentiram-se desafiados para a construção desse objeto de aprendizagem - vídeos - experiência que até então não haviam vivenciado. Foram organizados em pequenos grupos (Fig. 1), sendo que cada grupo ficou responsável por uma temática e posteriormente ocorreu a socialização da produção desses saberes.

Constatou-se que cada grupo, por meio de suas habilidades, fundamentação teórica e criatividade organizaramse de forma diferenciada, mas todos conseguiram relacionar a temática trabalhada à área da docência e, especialmente, perceberam a importância do uso da tecnologia para qualificar ainda mais o planejamento da ação docente.

Esse conhecimento construído pelos acadêmicos pode ser verificado nos relatos a seguir: 
Para a elaboração desse objeto de aprendizagem foram realizadas pesquisas sobre o tema, seleção de fotos, pesquisas na internet, seleção de músicas, além do conhecimento sobre a temática. Também tivemos que buscar conhecimentos tecnológicos para a elaboração do vídeo. Assim, a produção deste objeto apontou um caminho diferente e uma opção a mais na organização da nossa futura prática docente. $(\text { Al })^{1}$

E mais,

A produção do vídeo em um contexto educacional nos permite planejar nossas aulas de forma mais dinâmica e criativa. Representa uma ferramenta pedagógica que auxilia na aprendizagem dos alunos, complementando assim a mediação do professor. (A13)

Também,

Tivemos que estudar, filmar e filmar muitas vezes até que conseguíssemos produzir um vídeo educacional contextualizado sobre a concepção de planejamento escolar. (A11)

Dessa forma, os acadêmicos perceberam a importância do uso da tecnologia da informação para a organização da prática docente. Perceberam também que a utilização desses objetos de aprendizagem constitui uma possibilidade para o professor trabalhar conceitos e conteúdos de forma mais dinâmica e interativa; torna o aprendizado mais interessante e significativo, melhorando a motivação e a atenção dos alunos; também permite que os alunos relacionem novos conteúdos com os que já sabiam, ou seja, permite a construção de conhecimentos (Fig. 2).

Enfim, compreenderam que:

Há diversas possibilidades de utilização dos objetos de aprendizagem, mas todos devem ser usados de acordo com os objetivos educacionais propostos no planejamento e acima de tudo atender as necessidades de aprendizagem dos alunos. (A10)

E ainda perceberam que:

Os objetos de aprendizagem constituem uma ferramenta pedagógica criativa que auxilia no processo de aprendizagem dos alunos, complementando assim a mediação do professor. (A2)

Também,

A utilização dos objetos de aprendizagem no planejamento docente proporciona ao aluno uma nova experiência, nova vivência que sempre traz a construção do conhecimento. (A7)

Dessa forma, os acadêmicos também perceberam que a utilização de objetos de aprendizagem exige planejamento intencional, monitoramento e avaliação, a fim de contextualizar as necessidades e possibilidades de aprendizagem dos alunos, bem como (re)direcionar os objetivos da disciplina.

Verificaram que existem vários tipos de objetos de aprendizagem, mas que para o exercício reflexivo da docência o professor deve ser capacitado para utilizar todos os recursos da tecnologia computacional como uma ferramenta, lembrando sempre que ele e o aluno constituem sujeitos do processo de construção significativa de conhecimentos.

\footnotetext{
${ }^{1}$ Com o intuito de manter sigilo da identificação dos dezessete acadêmicos participantes desse estudo, os mesmos foram denominados pela letra A e numerados de 1 a 17 (A1 a A17)
}

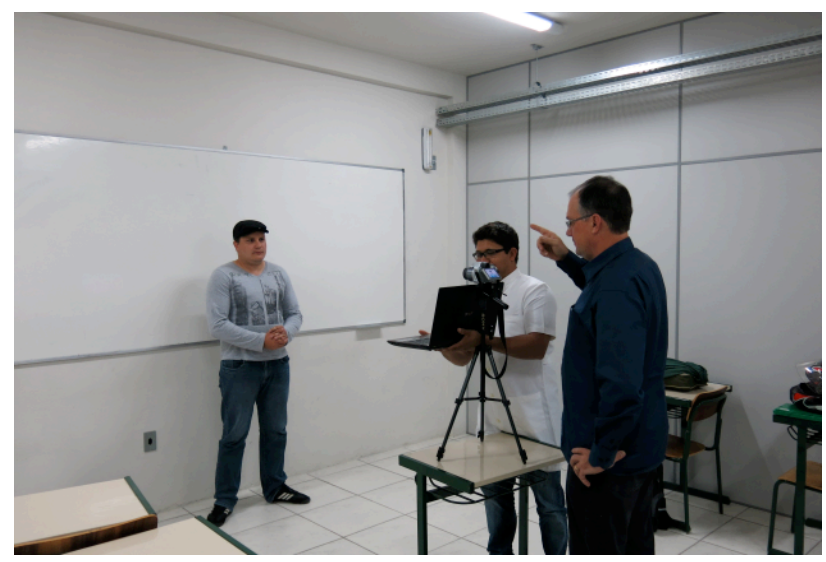

Figura 1. Acadêmicos do curso de Licenciatura em Ciências Agrícolas, Instituto Federal Catarinense-Câmpus de Araquari, durante a produção do vídeo educacional.

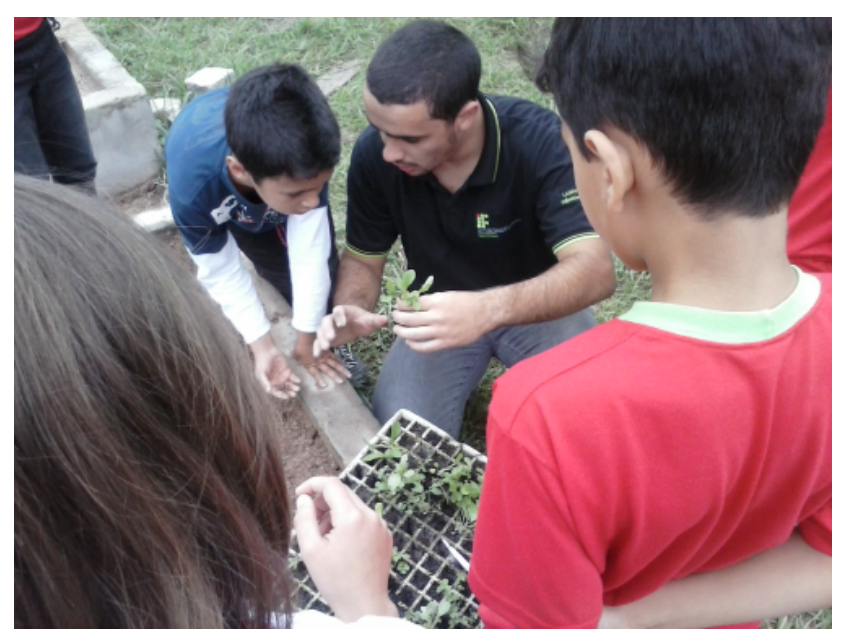

Figura 2. Atividade de construção do conhecimento de alunos através de atividade de vivência em campo.

Garcia (2005) [7] ressalta a importância de os professores terem oportunidades de refletir sobre os procedimentos didáticos e metodológicos que utilizam em suas aulas, aprimorando os seus conhecimentos, competências e disposições, o que lhes permitirá "intervir profissionalmente no desenvolvimento do seu ensino, do currículo e da escola, com o objetivo de melhorar a qualidade da educação que os alunos recebem" (GARCIA, 2005, p. 26) [7].

A formação de professores tem sido pauta obrigatória nas discussões que visam à busca de melhorias para o processo ensino e aprendizagem. Considera-se o professor agente social nesse processo, e o seu papel assume proporções importantes quando pensamos na sua atuação na sala de aula e na escola e no contexto social. Nesse sentido, é necessário que o professor tenha autonomia intelectual, pois além de saber e saber fazer, ele deve compreender o que faz e por que faz.

No entanto, para alcançar a autonomia intelectual os professores necessitam de formação teórica e da concretização da teoria na prática, que permitam que os conhecimentos apreendidos, de diferentes naturezas e experiências, possam ser experimentados em tempos e espaços distintos, de maneira crítica e reflexiva.

Nesse sentido, considera-se que a reflexão sobre a prática pedagógica, especialmente no processo de formação inicial, possibilita aos futuros licenciados a construção de saberes importantes que compõem a identidade docente. 
Sobre a produção de saberes no processo de formação inicial, Freire (1996) [8], argumenta que é necessário que o professor compreenda que um dos saberes indispensáveis para a prática docente é assumir-se como sujeito também da produção do saber, compreendendo que ensinar não é transferir conhecimento, mas ensinar é mobilizar uma diversidade de saberes e criar possibilidades para a sua produção ou a sua construção. Freire (1996, p.44) [8], ainda enfatiza que no processo de "formação permanente do professor, o momento fundamental é o da reflexão crítica sobre a prática. É pensando criticamente a prática de hoje ou de ontem que se pode melhorar a próxima prática".

Nessa perspectiva a construção de objetos de aprendizagem sobre o planejamento escolar possibilitou que os acadêmicos pensassem de forma reflexiva sobe a organização da ação docente; percebessem os desafios que os docentes vivenciam durante o processo de organização de sua ação educativa e que para superar tais desafios é necessário buscar na literatura pedagógica, na troca de experiências com os colegas e na utilização de diferentes recursos didáticos e tecnológicos, soluções para responder aos diversos desafios da prática escolar.

A construção de tais saberes é muito importante na formação inicial de professores, especialmente para a atuação profissional do licenciado em Ciências Agrícolas que poderá atuar nos diversos níveis da educação formal e não formal, especialmente na educação do campo; escolas agrícolas; secretarias da agricultura, planejamento e meio ambiente e em programas de extensão rural e pesquisa.

Nesse sentido, considera-se que para a construção de conhecimentos necessários à docência, é imprescindível que este esteja organizado de tal forma que proporcione ao futuro professor um profundo conhecimento da realidade, para que possa conhecer e compreender a sua complexidade e posicionar-se criticamente perante os acontecimentos sociais, educacionais e políticos, bem como sólida fundamentação teórica, por meio da qual estabelecerá relações com o contexto social e escolar, permitindo-lhe interpretá-los e intervir de forma consciente e crítica.

Alarcão (2001) [9] explica que é impossível conceber um professor que não se questione e busque informações sobre os encaminhamentos mais adequados para resolver os desafios da prática docente, que não se questione perante a dificuldade de alguns alunos, que não se pergunte durante a correção das atividades avaliativas porque os alunos não compreenderam o conteúdo, que não leia criticamente os manuais ou as propostas didáticas que lhe são feitas, que não se questione sobre as funções da escola e especialmente sobre a sua função enquanto sujeito-ator do processo ensino-aprendizagem, viabilizando desta forma, a aquisição de uma postura investigativa na prática profissional e social, especialmente na ação de planejar a prática docente.

Nesse sentido, durante a socialização dos vídeos produzidos indagou-se aos acadêmicos se a utilização de objetos de aprendizagem viabiliza a construção significativa de conhecimentos e saberes e como deve ser essa utilização pelo professor.

Eis algumas respostas:

Não há limites na utilização de objetos de aprendizagem na prática pedagógica, mas eles devem ser utilizados com intencionalidade, isto é, considerando os objetivos educacionais propostos para aquela aula. (A7)

A utilização de objetos de aprendizagem é uma ferramenta pedagógica que solidifica a construção de novos conhecimentos, pois os alunos exercitam outras funções além de ler, escrever e copiar. Quanto à utilização dos objetos de aprendizagem na organização da prática pedagógica, além de dominar o uso da tecnologia, o professor deve apresentar domínio sobre o conteúdo que está ministrando. (A5)

A realização desse projeto proporcionou aos acadêmicos a compreensão do uso pedagógico das novas tecnologias, especialmente dos objetos de aprendizagem, representando um novo espaço educativo que permite ampliar as reflexões sobre o papel das tecnologias da informação e comunicação na educação e a possibilidade de colocar em prática novas situações didáticas que se caracterizam essencialmente pela aprendizagem colaborativa entre os sujeitos envolvidos no processo de ensinar e de aprender. Sobre a construção de saberes Tardif (2002) [10], afirma que os professores possuem, desenvolvem e adquirem saberes variados e heterogêneos e que não provêm de uma fonte única, mas de várias fontes e diferentes momentos da história de vida e da carreira profissional.

A construção de saberes vivenciada pelos acadêmicos pode ser observada no relato abaixo:

A utilização do vídeo como objeto de aprendizagem me mostrou um caminho diferente e uma opção a mais no preparo das aulas e na mediação diferenciada do conhecimento. (A8)

Segundo Almeida (2008, p. 477) [11] no processo de formação inicial é necessário mobilizar

saberes teóricos e práticos capazes de propiciar o desenvolvimento das bases para que o professor investigue sua própria atividade e, a partir dela, constitua os seus saberes num processo contínuo, de modo a se colocar como sujeito de suas práticas, analista do contexto em que atua, articulador dos conhecimentos teóricos com as dinâmicas sociais e as necessidades de aprendizagem de seus alunos.

A autora ainda ressalta que certamente, formaremos um docente que poderá problematizar a realidade com a qual irá se defrontar, adotando uma prática docente investigativa que colabore com a formação de um cidadão responsável e compromissado como seu entorno social.

Portanto, podemos afirmar que os acadêmicos do curso de Licenciatura em Ciências Agrícolas vivenciaram por meio desse projeto a construção de saberes importantes para a sua atuação enquanto profissionais da educação que deverão fazer de sua prática pedagógica e social um processo contínuo de investigação.

\section{CONSIDERAÇÕES FINAIS}

O desenvolvimento desse estudo em um curso de licenciatura permitiu constatar a importância de os professores, especialmente os que se encontram em processo de formação inicial, terem oportunidades de refletir sobre as possibilidades de utilizarem procedimentos didáticos mediados pelas novas tecnologias da informação, especificamente pelos objetos de aprendizagem.

Esse projeto também permitiu que os acadêmicos percebessem no campo educacional, que a internet surge como uma importante ferramenta para alavancar a quali- 
dade no processo de aprender e de ensinar, estabelecendo canais de comunicação e interação que representam novas perspectivas de acesso e construção colaborativa do conhecimento. Também lhes permitiu compreender que o uso das novas tecnologias possibilita ao professor intervir profissionalmente na qualificação do ensino, com vistas a melhorar a qualidade da educação por meio dos objetos de aprendizagem.

Portanto, a produção de um vídeo, como objeto de aprendizagem possibilitou aprimorar os conhecimentos e as competências dos acadêmicos na área da docência, constituindo um espaço e tempo de construção de aprendizagens significativas no processo de formação inicial de professores.

\section{AGRADECIMENTOS}

Os pesquisadores responsáveis por este estudo agradecem a colaboração dos acadêmicos do quinto semestre do Curso de Licenciatura em Ciências Agrícolas do Instituto Federal Catarinense - Câmpus Araquari/2013.

\section{REFERÊNCIAS}

[1] V.M. Kenski. "Tecnologias e ensino presencial e a distância", 3ed. São Paulo: Papirus, 2006.

[2] E. Lampert. "A universidade e o currículo: possibilidades de redimensionar o fazer-pedagógico". Linhas, vol. 10, n. 02, pp. 144 - 155, jul. / dez. 2009.

[3] L.F. Veríssimo. "Tecnologia". Postado em 24 de abril de 2009. Disponível em: http://lendoeaprendenddo.blogspot.com/2009/04/tecnologia-luisfernando verissimo.html. Acesso em: 06 de Maio de 2013.
[4] J. Moran. Educação On-line. São Paulo: Loyola 2003.

[5] IEEE. Institute of Electrical and Electonics Engineers. Apresenta textos sobre objetos de aprendizagem. Disponível em: $<$ http://tsc.ieee.org/wg12/index.html . Acesso em: 18 Agosto. 2013.

[6] P.A. Behar. Modelos pedagógicos em educação a distância. Porto Alegre: Artmed, 2009.

[7] C.M. Garcia. Formação de professores. Portugal: Porto Editora, 2005.

[8] P. Freire. Pedagogia da autonomia: saberes necessários à prática educativa. 15 ed. São Paulo: Paz e Terra, 1996.

[9] I. Alarcão. Escola reflexiva e nova racionalidade. Porto Alegre: Artmed, 2001.

[10] M. Tardif. Saberes docentes e formação profissional. Petrópolis: Vozes, 2002.

[11] M.I. Almeida. "Ensino com pesquisa na licenciatura como base da formação docente" in: ENDIPE - Encontro Nacional de Didática e Prática de Ensino - Anais, vol. 14. Porto Alegre, 2008, pp. 473487.

\section{AUTORES}

Gislene M.C. Raymundo - Instituto Federal Catarinense, Câmpus Araquari, Rod. BR 280, km 27, AraquariSC (gislene.miotto@ifc-araquari.edu.br).

Sandra M. Cunhasque - Instituto Federal Catarinense, Câmpus Araquari (sandra.cunhasque@ifcaraquari.edu.br).

André L.F. Souza - Instituto Federal Catarinense, Câmpus Araquari (andre.fachini@ifc-araquari.edu.br).

Submitted 19 March 2014. Published as re-submitted by the authors 05 April 2014 